\title{
LOS TERCIOS CATALANES DURANTE EL REINADO DE CARLOS II, 1665-1697. EL FUPCIONAMIENTO INTERNO DE UNA INSTITUCIÓN MILITAR
}

\author{
Antonio Espino López*
}

Nuestra intención en el presente trabajo no ha sido analizar la actuación militar de las tropas pagadas por el Principado de Cataluña durante los conflictos del reinado de Carlos II, sino, más bien, interesarnos por el funcionamiento interno de los tercios catalanes como institución, así como de toda una serie de factores que podríamos denominar el "día a día" de dichas formaciones tanto en campaña como en momentos en los que se hallaban de guarnición. Las problemáticas personales, las enfermedades, los salarios, las aspiraciones socioeconómicas o los delitos que padecieron, soportaron, cometieron o de los que se beneficiaron estos hombres nos ayudan a entender mejor la época que tratamos desde una óptica militar, o, mejor aún, socio-militar tan desconocida -y nos atrevemos a decir tan denostada-- historiográficamente en nuestro país. La importancia del hecho militar en todas las épocas, por lamentable que nos pueda parecer, no admite que se sigan desconociendo, o conociendo parcialmente, los aspectos militares, en este caso, de la época de los Austria.

Durante el reinado de Carlos II, los continuos conflictos con Francia -Guerra de Devolución (1666-1667), Guerra de Holanda (1673-1678), Guerra de Luxemburgo (1683-1684) y Guerra de los Nueve Años (1689-1697)- obligaron a Cataluña a participar en la lucha. No era algo nuevo. Entre 1637 y 1659 el Principado había estado inmerso en un clima de guerra continua. La participación catalana dentro del bando real se canalizó a través de tercios pagados por las instituciones catalanas. Cuando las agresiones francesas de la época de Luis XIV así lo requirieron, la Corona se iba a encontrar con que reinos como Navarra, Valencia, Aragón y la propia Cataluña, además de Castilla, contaban con una cierta tradición a la hora de levar y mantener tercios para la guerra en las

\footnotetext{
* Universitat Autónoma de Barcelona
} 
fronteras peninsulares. Para los virreyes, los tercios catalanes tenían algunas ventajas: sobre todo la rapidez con la que se levaban, "assí por executarse en el mismo Principado en que se ahorra la dilación de conducirlas de otras partes, como porque aunque estas sean también nuebas, son de gente que se han criado entre el ruido y manejo de las armas teniendo desde sus primeros años por diversión los militares exercicios"1.

\section{Funcionamiento interno}

Una vez recibida la carta del monarca demandando la recluta de un tercio, por regla general las instituciones catalanas aceptaban sin vacilar la realización de dicha petición, pero solían regatear el número de hombres que comprendería dicho tercio. Tarea del virrey era intentar que la fuerza reclutada tuviese el mayor número posible de hombres. Por otro lado, el servicio se hacía por toda la campaña y mientras durase la guerra, de modo que las instituciones iban a ser presionadas para que realizasen continuas levas con el propósito de reforzar sus tercios o bien de reclutar otros para enviarlos al frente como refuerzos. En varias ocasiones -1675, 1678, 1684, 1693, 1694- se enviaron tercios de socorro, mientras que desde 1695 y hasta el final de la Guerra de los Nueve Años, en 1697, el Principado iba a reclutar dos tercios provinciales, amén del enorme esfuerzo que hizo toda Cataluña pagando tropas para la defensa de Barcelona en 1697. Tras el final de la campaña, y pidiendo previamente permiso al virrey, se licenciaban los hombres que no quedaban guarnicionando alguna plaza. Todos cobraban hasta el día de la licencia y los enfermos ingresados en cualquiera de los hospitales lo hacían hasta que se reponían y podían marchar a sus casas.

Por voto secreto, los consellers de Barcelona o los diputats de la Generalitat elegían al maestre de campo y al sargento mayor del tercio. Posteriormente se nombraban los capitanes de las compañías. El proceso continuaba sacando seis personas de la Vint-i-quatrena de Guerra que, junto a los consellers, se encargarían del negocio del tercio. Si bien tanto la Ciudad Condal como la Generalitat tenían esta facultad, era el rey quien, en última instancia, daba el visto bueno al expender las patentes para el cargo de estos oficiales. Normalmente, el monarca aceptaba los elegidos por las instituciones catalanas ${ }^{2}$. Es evidente que tales puestos eran atractivos, dado que la paga era considerada como buena, incluso mejor que la ofrecida por el rey en el ejército, pero había un handicap: era difícil realizar carrera en las filas de los tercios pagados por las

1. A(rchivo) C(orona) A(ragón), C(onsejo) A(ragón), Leg. 232, virrey Escalona-Villena al CA, 17-VI-1694

2. No era este el caso del Reino de Galicia. Los diputados de las ciudades gallegas reclamaron ante el Consejo de Estado la posibilidad de elegir a quienes ellos quisieran para los puestos de maestre de campo y sargento mayor. El Consejo de Estado no accedió alegando que ellos, a diferencia de valencianos, catalanes o aragoneses, no hacían tercios, sino compañías sueltas. A(rchivo) G(eneral) S(imancas), Estado, Leg. 4133, consulta del C(onsejo) E(stado), 21-111-1684 
provincias, dado que el servicio terminaba al finalizar el conflicto. Para evitarlo, los aragoneses habían conseguido que los oficiales de sus tercios fuesen acogidos en el Ejército Real para continuar su carrera, si así lo deseaban, una vez finalizado el servicio. Los tercios pagados por el reino de Valencia también contaban con esta gracia. Dicha posibilidad se les negó a los catalanes en 1684, habiéndola reclamado sistemáticamente, argumentando la Corona que dicha merced se les hizo a los aragoneses al mantener ellos, por voto en cortes, su tercio durante veinte años ${ }^{3}$. Lo interesante, es que a la propia Corona o, más bien, a militares de carrera, como el virrey de Cataluña, duque de Bournonville, no se les escapaba que los tercios catalanes formaban buenos soldados y era una lástima que no pudieran continuar su carrera en el Ejército Real por falta de dinero. Por cierto que Cataluña tampoco estaba dispuesta a mantenerlos sin conflicto abierto, como pretendía el virrey ${ }^{4}$.

Una vez elegidos los oficiales, las comisiones de recluta de ambas institui ones proponían que ni el veedor ni el pagador de los tercios pudiesen alistar a nadie sin la presencia del maestre de campo o del sargento mayor, controlando éstos que los individuos no fuesen fugados de otras agrupaciones. El Consell de Cent exigía que todos los alistados fuesen catalanes, de 17 a 40 años, bien constituidos físicamente y aptos para la guerra. La Generalitat, en cambio, estuvo levando gente mayor de 19 años hasta 1697, cuando comenzó a levar a mozos con 18 años. En relación a la edad de leva, contamos con escasos ejemplos al haberse perdido casi todos los libros con las filiaciones de los alistados. El tercio del Consell de 1667-1668 tenía un 11,38\% de sus integrantes por debajo de los 18 años, mientras que el de 1674 había corregido dicha deficiencia reduciéndola al 5,14\%. En uno de los tercios provinciales de 1695, el del maestre de campo J. Copons, sólo el 4\% de los hombres tenía menos de 18 años. En los tres casos, la amplía mayoría de los soldados se situaban entre los 18 y los 30 años: un $67,79 \%$, un $75,31 \%$ y un $74,88 \%$, respectivamente. Observamos, pues, que, claramente, estos tercios están conformados por hombres jóvenes, adecuándose bastante la realidad a la normativa de la leva, que, como hemos dicho, especificaba la prohibición de alistar menores de 18 años. Por necesidades de la leva, no obstante, el Consell terminó alistando personas de fuera de Cataluña. En su tercio de 1667-1668 había alistados 44 foráneos: once italianos, doce del RoseIlón, Conflent y Capcir, un francés, diez aragoneses, cuatro valencianos y tres granadinos. En el caso del tercio de 1674, 81 hombres -14,36\%-procedían de fuera del Principado: cincuenta de la Cataluña francesa -el fracaso de la Conspiración antifrancesa de Vilafranca de dicho año sin duda influyó-, ocho mallorquines, cuatro valencianos, otros cuatro castellanos, tres aragoneses, tres flamencos, cinco italianos, tres franceses y un vasco. Durante la Guerra de los

3. ACA, CA, Leg. 336, consulta del CA, 27-I-1684. A(rchivo) H(istórico) M(unicipal) B(arceIona), consellers, Lletres closes, Vol. 105, consellers a Carlos II, 15-I-1684

4. ACA, CA, Leg. 330, consulta del CA, 23-11-1684 
Nueve Años, en 1691, se comenzó a reclutar naturales no catalanes de la Corona de Aragón y algunos capitanes comenzaron a enganchar hombres a su tercio fuera de la Ciudad, en Manresa, Valls, Reus y Vilafranca del Penedés ${ }^{5}$. En líneas generales, según los pocos ejemplos con los que contamos, nos aventuramos a decir que la mayor parte de los alistados catalanes proceden de Barcelona y del entorno comarcal -más bien de la veguería a la que pertenecen, en esta época, así como de las zonas más pobladas y cercanas al teatro de la guerra. Siempre que la paga sea alta, muchos campesinos, pero también muchos jóvenes artes anos se alistan, sobre todo si tienen confianza -cuando eran convecinos-en el oficial que les guiaría; si pensaban desertar se alistarían en compañías de stras villas para no ser buscados en sus lugares de origen ${ }^{6}$.

Desde un principio, la Generalitat podía alistar tropas en todo el territorio catalán, de ahí que no existiese una competencia frontal, al menos en teoría, con el Consell de Cent. Justamente por esta causa, los capitanes reclutadores de la Generalitat debían llevar fuertes sumas de dinero, pues nadie que sentaba plaza quería esperar a llegar a Barcelona, donde se reunían todos los hombres, para disponer de su paga de enganche ${ }^{7}$. En el caso del Consell de Cent, estaba prohibido a los oficiales reclutar hombres por su cuenta, ya que sólo en Barcelona podía el veedor alistarlos. Es la única diferencia entre ambas instituciones $^{8}$. Asimismo, en 1696 se tomó la decisión de expulsar a todos los franceses alistados en los tercios catalanes, lo que implica que los hubo".

5. AHMB, consellers, Guerra, Vols. 12 y 13, libros de los tercios de 1667-1668 y 1674. AHMB, consellers, Deliberacions, Vol. 200, 25-V-1691. En el caso del tercio provincial de 1695, tercio de don Joan Copons, el 10,35\% de los alistados no procedían del Principado. Véase ACA, Generalitat, G-119/2

6. De nuevo, disponemos de pocos ejemplos. El tercio de don Joan Copons, a partir de 650 casos donde se especifica el oficio, de un total de 925 hombres que integran el tercio, nos da como resultado un $49,5 \%$ de campesinos -pagesos y hortolans. El resto, artesanos, repartidos hasta sesenta oficios diferentes. En el caso del tercio de Barcelona de 1674 -el único que permite la comparación-, un 55,77\% de los alistados eran artesanos, por tan sólo un $35,42 \%$ de campesinos. Una explicación posible, además del dinero a percibir como soldada y la cuota de enganche que se entregase, es que en 1674 nos hallamos en los inicios de la Guerra de Holanda, siendo más factible, entonces, levar gente en las ciudades. En el caso del tercio Copons, nos encontramos en 1695, tras muchos años de guerra y con parte del país invadido, lo cual explica que muchos campesinos desplazados de sus tierras por las acciones del enemigo se alistaran como último recurso para obtener ingresos. Véase: ACA, Generalitat, G-119/2 y G-119/3.AHMB, Consellers, Guerra, C-XVI-13

7. ACA, Generalitat, Lletres trameses, Vol. 883, diputats al capitán Bellver, 27-V-1689. Los salarios eran iguales a los del tercio de 1684

8. ACA, Generalitat, Lletres trameses, Vol. 881, Generalitat a diputats de Girona, 16-V-1684. A menudo, como en este caso, se pedía a otras instituciones o a particulares que adelantasen dinero para poder pagar puntualmente a los tercios. AHMB, consellers, Lletres closes, Vol. 105, consellers a obispo de Girona, 3-VI-1684. AHMB, consellers, Deliberacions, Vol. 193, 24 de guerra, 17-VI-1684.

9. ACA, Generalitat, capitán Taverner a los diputats, 24-III-1696. 
La leva se pregonaba en los lugares "habituales" de Barcelona, que desconocemos, mediante pífanos y tambores contratados para tal fin, que iban alentando a la población. Luego, los sargentos se dedicaban a ir consignando en los libros de registro los datos personales y físicos de los reclutas ${ }^{10}$. Si era el caso, se enviaba un mensajero a otras poblaciones para informar de la leva que se hacía y sus condiciones. En el momento de iniciar la leva se debía confeccionar una bandera, que quedaba instalada en la casa del Consell o de la Generalitat, bajo la cual quedaban inscritos los hombres. Cuando dicho proceso terminaba, se preparaban las cajas de guerra del tercio, para el dinero y el $m$ aterial de administración, y se encargaba una bandera de combate, de tafetán blanco con una cruz roja o carmesí también de tafetán, en el caso de la Generalitat, que se renovaba cada año ${ }^{11}$.

Todos los alistados eran voluntarios, pagándose inmediatamente a los hombres la cuota de enganche. Lo habitual era pagar 3 libras catalanas en el momento de alistarse -unos 17 reales castellanos- y 4 sueldos catalanes al día como salario tanto el Consell de Cent como la Generalitat, pero la premura del tiempo, la necesidad de enviar tercios de socorro a la frontera o las dificultades para encontrar voluntarios hizo que las cuotas de enganche se incrementasen. Durante la Guerra de Holanda, en 1675, tras la mala experiencia de la campaña de 1674, cuando, por falta de tropas levadas en Cataluña, se abortó una posible invasión del Rosellón, las instituciones catalanas llegaron a pagar entre 16 y 33 libras de enganche. En 1678, el Consell se vio obligado a pagar once libras de entrada para completar su tercio ${ }^{12}$. En los años posteriores pareció controlarse tal dispendio. Así, la Generalitat en el tercio de socorro enviado a Girona en 1684 llegó a pagar 11 libras de entrada; en 1691, en la leva habitual de su tercio, pagó 5 libras y 10 sueldos, situación que pudo corregir hacia 1695. Pero en el tercio de socorro para la campaña de 1693 se vio obligada a pagar 16 libras y 10 sueldos de enganche. El Consell de Cent experimentó situaciones absolutamente parecidas. El salario diario de las tropas se mantuvo siempre en los 4 sueldos $^{13}$. En otras ocasiones, el señuelo para el enganche no era el dinero. Los

10. En los libros que se conservaban podemos observar la extrema escrupulosidad de la burocracia militar del momento, quedando anotadas todas las incidencias dignas de mención que le ocurrían a los soldados. Se describían, asimismo, el color del cabello, barba y bigote, color y forma de los ojos, la nariz y cualquier otra marca especial en la cara, sobre todo marcas de viruela, cicatrices, lunares, etc., así como la estatura. A título de ejemplo: "Llorenç Carreras..., edat 40 anys, mediana estatura, cabell, barba y bigotes castanys molt cubert, los ulls de perdiu amb un trench al costat del ull esquerra y un senyal de ferida a la barba sota el masclet". ACA, Gneralitat, G-114/1, compañía del capitán Viladomar, tercio de la Generalitat, 1693.

11. ACA, Generalitat, G-121/7, libro de cuentas del tercio, 1689-1692.

12. ACA, CA, Leg. 4324, virrey San Germán a F. Izquierdo, secretario del CA, 20-V-1675.

13. ACA, Generalitat, Deliberacions, Vols. 236 y 237. ACA, Generalitat, Lletres trameses, Vols. 883, 887, 889. ACA, CA, Leg. 462. ACA, CA, Leg. 336. AHMB, consellers, Lletres closes, Vol. 105. AHMB, consellers, Deliberacions, Vols. 201-206. 
estudiantes de Lleida que sirvieron en la compañía levantada en 1695 lo hicieron con la idea de obtener el grado de doctor sin tener que pagarlo ${ }^{14}$.

Los soldados recibían de forma gratuita un pan de munición diario, pagado por el rey, con un peso de 24 onzas -688 gramos-. Ahora bien, en el momento de ingresar en el tercio la tropa recibía uniforme y armamento, que no eran gratuitos. Cada tercio vestía de forma diferente -el tercio de la Generalitat de gris y rojo como era tradicional, el tercio del Consell de rojo, el tercio del conde Darnius de gris y rojo y el de don Joan Copons de gris y azul-, pasando el uniforme de costar 9 libras y 16 sueldos en 1678 a poco más de 13 libras hacia 1693, cantidad que le era restada al soldado de su estipendio a razón de dos sueldos al día hasta salir a campaña y un sueldo al día en campaña hasta que se completaba el pago ${ }^{15}$. La ciudad de Barcelona realizaba sus propios asientos para uniformar a sus hombres. Por ejemplo, en 1690 se gastaron 8.312 libras -48.209 reales de plata- en la indumentaria del tercio de aquel año ${ }^{16}$.

Una vez sentada la plaza y cobrada la cuota de enganche nadie podía borrar una plaza, es decir, salir del tercio, sin que el caso particular fuese juzgado por una comisión del Consell y los elegidos de la Vint-i-quatrena de Guerra. La Generalitat tenía idéntico funcionamiento. En algunos casos, cuando se retornaba la cantidad cobrada como cuota de enganche y se encontraba un sustituto, se podía abandonar el tercio. Todos los hombres debían llevar sus armas o comprar las que les hicieran falta; en todo caso, serían armados antes de salir a campaña, pero ello no siempre era factible.

Los salarios de los tercios resultaron relativamente inalterables desde los designados en 1667:

Maestre de campo: 116 libras/mes.

Sargento mayor: 65 libras/mes.

Ayudantes: 20 libras/mes.

Alférez de maestre de campo: 20 libras/mes.

Capellán mayor: 15 libras/mes.

Cirujano mayor: 15 libras/mes.

Furriel mayor: 15 libras/mes.

Tambor mayor: 8 libras/mes.

Estos oficiales conformaban la denominada Plana Mayor del tercio. El maestre de campo tenía derecho a seis plazas de criado con un salario de seis libras al mes cada uno. El sargento mayor disponía de tres criados y los capitanes de uno. A su vez, cada compañía estaba formada por:

14. Informe al respecto en ACA, CA, leg. 471, virrey Velasco a Carlos II, 26-1-1697.

15. ACA, Generalitat, Deliberacions, Vols. 231, 237.

16. AHMB, Consell, Deliberacions, II-198, 30-IV-1689. Idem, Consell, Manual, XIII-69, asiento de uniformes de los soldados, 4-V-1689. El uniforme tenía un coste de 10 libras, 15 sueldos y 6 dineros. Este precio fue subiendo. Idem, Deliberacions, Vol. 199, gastos del tercio, 1690. 
Capitán: 44 libras/mes.

Alférez: 18 libras/mes.

Sargento: 7 libras y 10 sueldos/mes

Cap d'esquadra (cabo): 7 libras/mes

Soldado: 6 libras/mes.

A partir de 1684 se introdujeron algunos cambios: el sargento pasó a cobrar 9 libras, el tambor mayor 10 libras, el alférez 19 libras, el alférez de maestre de campo 24 y, desde 1689, 30 libras cada mes. Los veedores y contadores pasaron de 50 libras en 1684 a 90 y 80 libras, respectivamente, en 1689 . El resto de los salarios quedaron inalterables. Los oficiales que pasaban al Ejército Real sólo cobraban dos terceras partes del salario del grado que tenían ${ }^{17}$. Asimismo, la Generalitat intentaría encuadrar las levas realizadas por las veguerías en 1697 en tercios -cuatro, en concreto, llamados Almogávares-con un salario sensiblemente inferior al hasta ahora visto. El maestre de campo sólo cobraba 90 libras, el sargento mayor 50, los capitanes 30 o los alféreces $15^{18}$. Ahora bien, todo el mundo, en cualquier circunstancia, ya fuese enfermedad, estar prisionero o con permiso de ausencia del tercio, cobraba su sueldo ${ }^{19}$. Hubo alguna protesta por motivos salariales. El capellán mayor del tercio del Consell en 1689, Dr. Joan Esteve, protestó porque su salario, a diferencia del de los capellanes de otros tercios, era más bajo y tampoco contaba con la ayuda de costa de la misa del tercio ${ }^{20}$. También se quejaron de su sueldo los sargentos del tercio de socorro de la campaña de 1693. Decían que habían cobrado igual que los soldados, cuando su soldada no sólo era normalmente más alta, sino que además se lo habían ganado con creces al tener que enseñar a gente bisoña sin idea ni de armas ni de disciplina militar ${ }^{21}$.

El Consell de Cent hacía cálculos sobre el coste posible de su tercio, en 1684, para planificar su pago: se impondrían 14 sueldos por cada carga de vino clarete, con lo que se obtendrían 25.200 libras. Seis dineros por cada libra de cordero y tres sueldos por cada libra de cerdo consumidas en Barcelona, lo que montaría 16.900 libras. Un sueldo por cada libra de tabaco, otras 3.000 libras, otro sueldo por cada medida de aceite que entrase en la ciudad, montaría

17. ACA, Generalitat, Lletres trameses, Vol. 881, "Instructions per lo vehedor del tercio del General...", abril, 1684. ACA, Generalitat, G-121, libro de cuentas del tercio de la Generalitat, 1689-1692. AHMB, consellers, Guerra, C-XVI-12, Libro del tercio, 1667-1668. AHMB, consellers, Deliberacions, Vol. 193, gastos del tercio, 1684.

18. AHMB, Al. legacions Jurídiques, serie IV, cajas 8 y 9 , Generalitat, 1684-1713.

19. Cuando cayó preso la mayor parte del tercio de la Generalitat con su maestre de campo, Marimon, al frente, los diputats, a través de mercaderes, les hacían llegar sus salarios. ACA, Generalitat, Lletres trameses, Vol. 885, diputats a Marimon, 13-I-1691.

20. AHMB, Consell, Lletres closes, VI-106, consellers al capitán Sagrera, 22-V-1689. Idem, Deliberacions, II-198, Vint-i-quatrena de Guerra, 28-V-1689. Idem, Consell, Manual XIII-69, Dr. Joan Esteve, 25-V-1689. Idem, consellers, Deliberacions, Vol. 198, carta de Joan Esteve, 27-XI-1689.

21. AHMB, Consell, Deliberacions, Vol. 202, sargentos del tercio al Consell, 3-XI-1693. 
5.000 libras. Por último, seis libras por cada carga de aguardiente que entrase o se fabricase en Barcelona, lo que permitiría obtener otras 2.000 libras $^{22}$. Entre 1667 y 1694, según las cifras que reflejamos en el Cuadro Núm. 1, el Consell de Cent alegaba haberse gastado 504.882 libras en sus tercios. En el caso de la Generalitat, las incompletas cuentas de las que disponemos nos señalan un gasto de 420.673 libras. Ahora bien, realizando una media de los gastos anuales de los tercios y multiplicando dicha cifra por todos los años que se levantaron tercios, dieciocho, más los tercios de socorro, tenemos que el Consell gastó no menos de 800.000 libras, mientras que la Generalitat hubo de gastar algo más de 600.000 libras, ello sin contar los gastos del Principado en las levas pagadas en 1677-1679, 1693 y 1695-1697, además del coste de los somatenes, alojamientos de tropas y bagajes.

El propio veedor acompañaba al pagador para controlar la libranza de la mesada correspondiente, yendo allí donde se encontrasen los soldados, pues se les pagaba en mano tanto a la oficialidad como a las tropas. Normalmente, se pagaba cada quince días a los oficiales, los días primero y decimosexto de cada mes, firmando en el libro de pagos -casi todos saben firmar. En el caso de no saber firmar o no estar presente, un compañero firmaba indicando por quien lo hacía. Los soldados cobraban cada tres días en mano, es decir, jamás el pagador abonaba la soldada a los oficiales. Si el soldado se hallaba realizando un servicio cobraba cunado regresaba. Cada mes el veedor debía enviar una relación de gastos y el número de soldados huidos para que el Consell o la Generalitat pudiesen hacer las diligencias oportunas. El veedor no sufragaba gastos por enfermedad. Si un soldado se hallaba enfermo se ingresaba en el hospital real o municipal más cercano sin pagar nada. En el momento de partir, el veedor debía cerciorarse de que los enfermos se hallaban realmente en el hospital, que no habían desertado, y cuando regresaban al tercio debían llevar oligatoriamente una fe del médico que les atendió donde constaría el tiempo de hospitalización para cobrar los atrasos correspondientes ${ }^{23}$.

\section{Número de tropas}

En los siguientes cuadros están reflejados los contingentes de tropas pagados oficialmente por Cataluña a lo largo de los años que nos ocupan.

Desde un primer momento, el número "oficial" de hombres de los tercios y el número "real" no tenían nada que ver. Más adelante examinaremos las causas principales de la pérdida de tropas - deserción, enfermedad, muerte, licencias concedidas por diversos motivos-, de momento comprobaremos las dificultades para mantener los tercios con un número operativo de hombres.

22. AHMB, consellers, Deliberacions, Vol. 193, consellers al virrey Boornonville, 25-1-1684.

23. A título de ejemplo, véanse las instrucciones para el veedor del tercio de la Generalitat de 1684 en ACA, Generalitat, Lletres trameses, Vol. 881, abril de 1684. 
CuAdro 1: Tercios del Consell de Cent, 1667-1697.

\begin{tabular}{lclc}
\hline \multicolumn{1}{c}{ Fecha } & No de tropas & Actuación & Coste \\
\hline $1667-1668$ & 300 & Campaña & $27.353 \mathrm{Ll}$. \\
1674 & 500 & Campaña & $40.035 \mathrm{Ll}$. \\
1675 & 400 & Socorro Girona & \\
$1675-1676$ & 500 & Campaña & \\
1677 & 500 & Campaña & $38.365 \mathrm{Ll}$. \\
1678 & 500 & Campaña & $46.827 \mathrm{LI}$. \\
1678 & 400 & Socorro Puigcerd... & \\
1684 & 537 & Campaña & $43.979 \mathrm{Ll}$. \\
1684 & 651 & Socorro Girona & $30.057 \mathrm{LI}$. \\
$1689-1693$ & 500 & Campaña & $176.154 \mathrm{LI}$. \\
1691 & 300 & Campaña/leva & " \\
1693 & 100 & Campaña/leva & \\
1693 & 600 & Socorro & $37.764 \mathrm{Ll}$. \\
1694 & 800 & Campaña & $64.348 \mathrm{Ll}$. \\
1694 & 500 & Socorro & \\
1695 & 1.000 & Campaña & \\
1696 & 500 & Campaña & \\
1697 & 800 & Campaña & \\
\hline
\end{tabular}

Fuentes: AHMB, Lletres closes, Vols. 105-111; Deliberacions, Vols. 193, 198-206; Albarans, Vol. 60; Guerra, Vols. 12-18.

CUADRO 2: Tercios de la Generalitat, 1667-1697.

\begin{tabular}{|c|c|c|c|}
\hline Fecha & № de tropas & Actuación & Coste \\
\hline $1667-1668$ & & Campaña & $28.326 \mathrm{LI}$. \\
\hline $1673-1678$ & & Campaña & \\
\hline 1684 & 500 & Campaña & $32.609 \mathrm{LI}$. \\
\hline 1689-1692 & 400 & Campaña & $359.738 \mathrm{LI}$. \\
\hline 1693 & 550 & Campaña & " \\
\hline 1693 & 1.000 & Socorro campaña & \\
\hline 1694 & 500 & Campaña & “ \\
\hline 1695 & 400 & Campaña & $"$ \\
\hline 1696 & 650 & Campaña & $"$ \\
\hline 1697 & & Campaña & $"$ \\
\hline
\end{tabular}

Fuente: ACA, Generalitat, G-114, G-121.

CUADRO 3: Levas de las veguerías/Tercios provinciales, 1677-1697.

\begin{tabular}{lcll}
\hline \multicolumn{1}{c}{ Fecha } & № de tropas & Actuación & Coste \\
\hline $1677-1679$ & 1.600 & Campaña & $66.248 \mathrm{LI}$. \\
1693 & 2.000 & Campaña & \\
1695 & 673 & Campaña & \\
1695 & 925 & Campaña & $22.390 \mathrm{Ll}$. \\
1697 & 6.106 & Junio-Agosto & \\
\hline \multicolumn{5}{l}{ Fuentes: ACA, Generalitat, G-99, G-119, G-122. } \\
\hline
\end{tabular}


ANTONIO ESPINO LÓPEZ

\section{Tercios del Consell de Cent}

El tercio del Consell de 1667-1668 contaba con una media de 250 hombres pagados por el veedor, pero entre julio de 1667 y junio de 1668 soportó 132 bajas por diversos motivos, que serían cubiertas mediante sucesivas levas. Al tener que pagar nuevas cuotas de enganche, todo el proceso se encarecía enormemente ${ }^{24}$.

A inicios de la Guerra de Holanda, en 1673-1674, el principal problema fue encontrar hombres dispuestos a levarse dado el descalabro sufrido en las primeras campañas. El Consell pudo levar antes su tercio que la Generalitat debido únicamente al enorme esfuerzo económico realizado tras pagar cuotas de enganche astronómicas. Con todo, hubo una pérdida de tropas importante. Los 504 hombres del tercio del Consell en marzo de 1674 pasaron a 399 en noviembre, una pérdida del 20,8\%. En mayo de 1675 sólo quedaban 202 y se imponía realizar una nueva leva. En marzo de 1677 el tercio, reconstituido, tenía 613 hombres. Unos meses de campaña bastaron para reducirlo hasta 434 plazas $-29,2 \%$ de pérdidas- en noviembre de dicho año. De nuevo en marzo de 1678 se consiguió incrementarlo hasta 582 plazas y en noviembre sólo quedaban $450-22,6 \%$ de pérdidas ${ }^{25}$.

En 1691, el Consell deliberó añadir a su tercio de 500 hombres una leva de 300 más englobados en tres compañías. El 25 de mayo se enarboló la bandera de leva. Una semana más tarde, y habiendo elegido ya a los tres nuevos capitanes, el Consell lamentaba que no hubiese sino sesenta alistados, a pesar de dar una dobla -cinco libras y diez sueldos catalanes- de entrada y cuatro sueldos al día como estipendio para la tropa. En vista de ello, la Vint-i-quatrena de Guerra accedió a la leva de naturales de la Corona de Aragón y comenzó a ali star tropas fuera de Barcelona ${ }^{26}$. Dos semanas más tarde, el primer grupo de refuerzo salía para el frente.

El 12 de enero de 1694 el Consell deliberó incrementar su tercio hasta los 800 hombres repartidos en ocho compañías. Seis días más tarde sólo había doce alistados, buscándose como solución el perdón de todos aquellos desertores que se presentasen voluntariamente en Barcelona. El 24 de mayo, y ante la marcha de la campaña, se hizo un nuevo tercio de 500 hombres $^{27}$. Gracias a las listas oficiales de pago del tercio, que sólo se conservan de mayo de 1694 a abril de 1695, podemos conocer la realidad de estas levas. El tercio de ochocientos hombres jamás contó con dicho número: en mayo de 1694 tenía 717

24. AHMB, consellers, Guerra, Vol. 12.

25. AHMB, consellers, Guerra, Vols. 13-17.

26. AHMB, Consell, Deliberacions, Vol. 200, Vint-i-quatrena de Guerra, 25-28-V y 1-VI-1691.

27. AHMB, Consell, Deliberacions, Vol. 203, Vint-i-quatrena de Guerra, 12-1-1694 y 29-V-1694. 
hombres, en septiembre quedaban 582 y en diciembre 438, un desceso de 279 plazas $-38,9 \%$ de pérdidas. Además, un informe de fines de septiembre aseguraba que en este tercio sólo había 447 hombres, es decir, 135 hombres menos que en el recuento anterior, y el tercio de 500 plazas se había reducido a 255 hombres. En cualquier caso, 702 plazas de un total de 1.300, un $54 \%$ de bajas ${ }^{28}$.

En 1695 la tónica fue la misma. Entre enero y abril se incrementó el tercio de 544 plazas a 962, con diez compañías, al aumentarse el tercio a 1.000 plazas. Pero en cuanto salió a campaña comenzaron las fugas: entre el 23 de marzo y el 29 de abril hay veinte huidos, tres muertos y treintaidós enfermos. A fines de octubre el tercio se había reducido a 528 plazas, un $54,8 \%$ de pérdidas respecto al número de hombres en abril ${ }^{29}$.

Las cifras consignadas indican pérdidas muy fuertes de efectivos, que unos achacaban a las muchas licencias del servicio concedidas por el Consell a los soldados -que iban desde motivos personales hasta por enfermedad, lo más usual-, situación aprovechada por aquéllos para quedarse en Barcelona tras su recuperación y no regresar al frente. Luego, ante la falta de voluntarios para el tercio, el Consell se veía obligado a perdonar a quienes se presentaban de nuevo al servicio, originándose una dinámica viciada y totalmente negativa. En realidad, en el trasfondo de esta situación se hallaba la voluntad del Consell de tener bien pagadas las tropas barcelonesas. Desde un principio, los soldados cobraban directamente de manos del pagador del tercio y, cuando marchaban con licencia a Barcelona, continuaban haciéndolo en la Ciudad, dando lugar al abuso, pues, como hemos dicho, la estancia se prolongaba indefinidamente en ocasiones. Así, algunos oficiales pedían ser ellos quienes pagasen a las tropas o, en su defecto, que quien marchase a curarse sólo tuviese ocho días de convalecencia pagados en la Ciudad Condal. Finalmente, la Vint-i-quatrena de Guerra ordenó que el tiempo de convalecencia fuese de un mes, considerando al individuo desertor si en dicho plazo no regresaba a su compañía ${ }^{30}$.

La Vint-i-quatrena de Guerra descubrió que en aquellos años más de 2.000 hombres se habían alistado en el tercio, indicando dicha cifra que todos o casi todos habían abandonado en alguna ocasión el tercio, con o sin licencia, siendo imposible de esta forma lograr una agrupación de gente veterana. A partir de los datos ya mencionados del tercio de mayo de 1694 a abril de 1695 se puede comprobar que la cifra anterior no es exagerada. Con 669 hombres en

28. AHMB, consellers, Guerra, C-XVI-18, pago del tercio de Barcelona, V-1694 a IV-1695. La cifra es 55.027 libras, sólo el tercio de 800 hombres. AHMB, Consell, Deliberacions, Vol. 203, muestra general del tercio de Barcelona, 28-IX-1694. A 147 hombres de esos 702 les faltaba el uniforme y la espada.

29. AHMB, consellers, Guerra, C-XVI-18, pago del tercio de Barcelona. AHMB, Consell, Deliberacions, Vol. 204, bajas del tercio hasta mayo de 1695. Ibidem, muestra general del tercio de Barcelona, 30-X-1695.

30. AHMB, Consell, Deliberacions, Vol. 204, Vint-i-quatrena de Guerra, abril de 1695. Idem, Deliberacions, Vol. 205, Vint-i-quatrena de Guerra, enero de 1696. 
ANTONIO ESPINO LÓPEZ

abril de 1694 -en un tercio de 800 plazas-, se reclutaron otros 48 hombres, para llegar a los 717 hombres de mayo; desde entonces se alistaron 319 hombres más. Contando a partir de los 669 hombres de abril de 1694, en abril de 1695 , es decir, en un año, pasaron por el tercio 1.036 hombres $^{31}$.

\section{Tercios de la Generalitat}

Los tercios pagados por la Generalitat se comportaron de forma parecida. Tenemos datos continuos durante la Guerra de los Nueve Años. De entrada, los 400 hombres prometidos de este tercio jamás estuvieron en campaña en 1689 y 1690. De los 357 hombres de junio de 1689, el tercio languideció hasta los 148 de diciembre de 1690. Dicha situación obligó a hacer una leva, y en julio de 1691 el tercio se componía de 490 hombres. Dicho año se reclutó en Granollers y en la zona comprendida entre Vilafranca, Igualada y Cervera y en Manresa. La orden para los capitanes reclutadores era de estar entre ocho y diez días en cada lugar, para pasar más tarde al siguiente. Lo más usual era enviar pequeños contingentes de reclutados a Barcelona, conducidos por un sargento que llevaba consigo el registro de las filiaciones. En junio se volvió a reclutar gente para el tercio, esta vez en Reus, pero pagando de entrada cinco libras y no las tres libras habituales ${ }^{32}$.

En 1692 se produjo una importante revolución interna en el tercio de Ia Generalitat. Todo comenzó cuando el virrey Medina Sidonia felicitó al Consell de Cent por su esfuerzo de guerra y no les dedicó ningún elogio a ellos, a pesar de haber pagado 550 hombres en 1691, según sus datos. La Generalitat se lamentó de no poder hacer nada más al carecer de las posibilidades económicas de Barcelona. Además, su tercio había permanecido en guarniciones sin salir a "lucirse" en toda la campaña. Para terminar con esta situación, los diputats pidieron al Consejo de Guerra que se les concediese la posibilidad de nombrar a don Josep Boneu como maestre de campo -cargo que ya ejercía en sustitución de don J. Marimon, preso en Francia-y a don Esteve de Bellet-capitán de dragones- como sargento mayor para dar mayor disciplina y eficacia a su tercio. Estas peticiones coincidían, precisamente, con un informe enviado al virrey por el auditor general del Ejército Real donde le explicaba la incapacidad de la Generalitat para castigar a sus tropas mientras estuviesen en Barcelona, dado que era prerrogativa del capitán general del ejército, en este caso, el propio virrey de Cataluña. ${ }^{33}$ En mayo de 1692 se hizo una recluta de otros cin-

31. AHMB, Consell, Deliberacions, Vol. 205, Vint-i-quatrena de Guerra, enero de 1696. AHMB, consellers, Guerra, C-XVI-18, pago del tercio de 1694-95.

32. ACA, Generalitat, Lletres trameses, Vol. 885, diputats al capitán Bru et alii, 15-24-30-III y 7-IV-1691. Ibidem, diputats al alférez. Flaquer, 8-VI-1691.

33. ACA, Generalitat, Lletres secretes, Vol. 915-918, diputats a su embajador en Madrid, 15-III y 12-IV-1692. ACA, CA, Leg. 464, Medina Sidonia a Haro, 2-V-1692. Informe del auditor general del ejército, 30-IV-1692. 
cuenta hombres en menos de una semana, pero el tercio sólo alcanzó los 445 hombres en julio y en seguida comenzó a disminuir.

En 1693 la Generalitat dio seis sueldos por día de soldada y hasta dieciséis libras y media como cuota de enganche para hacer, además de su tercio de 500 hombres, otro de 1.000. Con tales pagas no es de extrañar que, por ejemplo, se levantase una compañía de 150 hombres en Vic y su entorno en cinco días. Además, con intención de mejorar la capacidad bélica del tercio, se dio orden de quitarles la plaza a dos capitanes, dos sargentos y dos alféreces, dándoles la opción de permanecer en el mismo como soldados ${ }^{34}$. Ahora bien, en julio de 1693 sólo había 1.036 hombres levados, cifra que se redujo hasta 322 hombres en enero de 1694. En 1694 y 1695 la mayor novedad fue el problema de la Generalitat para mantener su tercio bien pagado. En enero de 1694 se le debía a la tropa un mes de paga y a los oficiales dos y medio. Meses más tarde, el número de hombres del tercio se había reducido muchísimo, cuando bastantes podían estar trabajando para particulares de las zonas del frente donde se hall aba el tercio de servicio ${ }^{35}$. Lo cierto es que en agosto de 1694 sólo quedaban 171 hombres. A lo largo de 1695 la cifra más nutrida del tercio fue en junio con 321 hombres.

En 1696 se decidió que el incremento del tercio de la Generalitat, cuyos ingresos habían disminuido por la porción de territorio conquistado por los franceses en 1694-1695, lo pagasen las ciudades de Tortosa, Tarragona, Solsona, Manresa, Balaguer, Vic y Lleida a razón de una compañía cada una de 40 a 45 hombres. En principio, la recluta sería pagada por dieciocho meses, cubriéndose las vacantes por fuga o inutilidad. Los meses siguientes fueron un continuo intercambio de misivas intentando que se respetasen los compromisos adquiridos. No obstante, la urgencia de la guerra obligó a los diputats a aceptar el número de hombres reclutados y la elección por las ciudades de los oficiales de sus compañías ${ }^{36}$.

El esfuerzo final se produjo en 1697. Ante el sitio de Barcelona, la Generalitat aseguraba al Consell de Cent que se hacían levas en toda Cataluña sin escatimar esfuerzos $^{37}$. En junio de dicho año, la Generalitat disponía de un tercio de 420 hombres, que se redujo justo en un $50 \%$ dos meses más tarde.

\section{Tercios provinciales de Cataluña}

Además de los tercios pagados por el Consell y la Generalitat, los diversos virreyes siempre buscaron obtener de Cataluña nuevas fuerzas que pudieran

34. ACA, Generalitat, Lletres trameses, Vol. 887, diputats al ayudante del Veedor, 7-III-1693.

35. ACA, Generalitat, Lletres trameses, Vol. 888, diputats a Maestre de Campo, 23-I-1694. Ibidem, diputats a J. Fontanills, ayudante del pagador, 25-V-1694.

36. ACA, Generalitat, Lletres trameses, diputats a Consuls de Tortosa, Tarragona, etc., 16-IV-1696.

37. AHMB, Consell, Cartes comunes, X-117, diputats a consellers, 6-VI-1697. 
encuadrarse de alguna forma en el Ejército Real. Según N. Feliu de la Penya, para las operaciones de 1673-1674, el virrey San Germán intentó que las veguerías pagasen 4.000 hombres integrados en nueve tercios para ayudarle en la hipotética reconquista del Rosellón. Pero, a lo hora de la verdad, Cataluña sólo pagó 1.800 hombres y, lo peor de todo, al fallar toda la operación, con el fracaso de la Conspiración de Vilafranca del Conflent, en dos días desertaron $500^{38}$. En 1677 y 1678 , el servicio de las veguerías terminó reduciéndose a dos tercios mal pagados, puesto que el donativo que había que realizar para costearlos aún no se había cobrado en $1679^{39}$.

El proyecto más importante, a nuestro juicio, para levantar un tercio en Cataluña pagado por los comunes del Principado data de 1689. El autor, anónimo, pero con toda probabilidad miembro de la Real Audiencia de Cataluña, defendía la creación de una agrupación de 1.000 hombres, pagada a perpetuidad por el Principado -aunque si invernaban se les reduciría la paga a la mitad o a una tercera parte- y reclutada a razón de un hombre por cada veinte fuegos. La entrada sería de cinco libras y media, dando el virrey el pan de munición y las armas. El principal problema era sacar a suertes los reclutas, por el lo el autor proponía "usar muy en secreto, y si fuera lícito juramentados, de otros medio y cautela prudente, y poco injusto, para hacer salir en suerte los hombres que le tocase de aquellos solos mozos más ociosos y inquietos, y en su defecto los menos perjudiciales a sus casas...". En cualquier caso, se advertía que el dinero obtenido se debería gastar exclusivamente en este servicio, "por [h] aberse otras veces el dinero divertido a otros fines que los propuestos ${ }^{\prime \prime 4}$. El plan se aplicaría con muchas variantes a partir de 1695.

En febrero de 1695, el virrey Gastañaga informaba a Carlos II de un madurado plan para levar en Cataluña 2.500 hombres en forma de milicias, que serían adscritas a dos tercios de nueva creación, de 1.000 hombres cada uno, y cinco compañías de cien hombres a incorporar a cualquier otro tercio. Una recomendación inicial era reducir dispendios en base a "la moderación de los excesivos gastos que se han hecho otras veces en las entradas...", ya fuese por falta de tiempo u otro motivo, de modo que pedía una cuota de enganche de tres libras y dos reales de ardites al día de estipendio, más el uniforme, "que no es pequeño cebo una golosina tan lucrosa". Días más tarde, la Generalitat contestó algunas de las características de este servicio, llegando a un acuerdo con el virrey. Este se conformó con una leva de 2.000 hombres de buena calidad dirigida por los diputats. La propia Generalitat elegiría la plana mayor de la oficialidad, que a su vez nombraría a los oficiales menores. El virrey Gastañaga se

38. FELIU DE LA PENYA, N.: Anales de Cataluña, Barcelona, 1709, Vol. III, p. 359. ACA, CA, Leg. 432, virrey San Germán a la regente, 7-IV-1674.

39. ACA, CA, Leg. 330, consulta del consejo, 23-II-1679.

40. B(iblioteca) N(acional), Ms. 2.399, "Proyecto para levantar un tercio de 1000 hombres...", dirigido al virrey Villahermosa, 3-VII-1689. 
comprometía a acoger en el Ejército Real a toda la oficialidad al licenciar los tercios siempre y cuando aquéllos fueran gente de calidad y con experiencia de mando. La advertencia final de Gastañaga nos recuerda las peculiaridades del gobierno de Cataluña: "Alguno (con poco conocimiento de la subsistencia desta provincia, de sus privilegios y del genio natural de sus [h] abitantes) puede ser que con celo indiscreto, o sedicioso, haia pensado en que por lo mismo que este Principado está bien dispuesto para todo lo que fuera del servicio de Vuestra Majestad que pudieren conceder, se le debiere mandar que conmutase el gasto de estas levas en vestir, remontar y pagar algunos cuerpos del exército, cotejando la quenta del importe, para tasarlos a una contribución fija, aunque esta sea accidental, por esta presente campaña, y aunque pudiera ser mejor establecido, sería tan malo aún para propuesto, ni imaginado, que desconcertaría (si se dijese) toda la armonía política y racional del afecto, firmeza y ternura con que este Principado ama, sirve y servirá a Vuestra Majestad mejor con la suavidad de sus Reales Insinuaciones que persuaden más estos genios que con las severas ordenes de precisión absoluta" ${ }^{\prime \prime 1}$.

La realidad fue muy diferente. El servicio de 2.500 hombres se transformó en dos tercios que, en abril de 1695, constaban de 673 y 925 hombres, respectivamente. No se buscó el incremento de estas tropas, sino conservarlas. La Generalitat insistía en el envío por adelantado de las mesadas para no dar opción a las fugas por falta de pagas. Por ejemplo, de los 212 hombres levados en la veguería de Vilafranca, 25 desertaron casi inmediatamente, exclamando el virrey que los enviaría a galeras si los atrapaba ${ }^{42}$. Por otro lado, se obligó a los lugares a pagar puntualmente las pagas de los soldados levados o sus sustitutos. El tema era peliagudo porque si no se les pagaba huían y si se les retribuía todo lo debido al mismo tiempo, dicha situación podía ser motivo para pensar en darse a la fuga, de ahí la necesidad de pagar casi diariamente ${ }^{43}$. El resto de la campaña fue un continuo tira y afloja entre los responsables de los tercios y la Generalitat, por un lado, y las veguerías por otro, por la cuestión del mantenimiento de los hombres, planeando siempre el enorme dispendio a realizar por un país muy quebrantado.

En 1696, la Generalitat pedirá levas de una duración de dieciocho meses. Toda la campaña transcurrió tratando con las villas sobre el servicio a realizar. El principal problema era que nadie quería levarse durante dos campañas seguidas y menos sin oficiales conocidos de sus lugares de origen -que siempre cuidaban mejor a sus convecinos. Por ello, todas las ciudades regatearon el servicio. Por ejemplo: a Vic se le pidieron sesenta hombres durante año y medio, pagando sólo cincuenta y por un año. Balaguer debía mantener cua-

41. ACA, CA, Leg. 468, Gastañaga a Carlos II, 5-II-1696.

42. ACA, Generalitat, Lletres trameses, Vol. 888, diputats a las veguerías de Cataluña, 16-24-IV y 4-VI-1695.

43. ACA, Lletres trameses, Vol. 889, diputats al pagador del tercio Darnius, 15-VIII-1695. 
renta hombres y pagar treinta libras cada mes, tras ofrecer un servicio monetario de 2.000 libras, pagó únicamente cuarenta hombres durante un año. A la Se u d'Urgell le fueron asignados 25 hombres, su respusta fue que o bien aportaría 550 libras, o bien pagaría diez hombres... Lleida debía mantener sesenta hombres y dar treinta libras cada mes, pidiendo que se le aceptase un donativo de 6.000 libras a cambio del servicio; finalmente pagó setenta hombres por un año. Tortosa fue de las pocas que cumplió lo asignado: mantuvo en campaña cincuenta hombres ${ }^{44}$.

En 1697 se continuaron haciendo levas a un ritmo nunca visto. La ciudad de Tarragona abonó una compañía de cien hombres, alegando que un esfuerzo tal no se hacía desde la mítica campaña de Salses, en 1637. A fines de junio, las levas de las veguerías de Cataluña sumaban 6.106 hombres encuadrados en 62 compañías $^{45}$.

\section{Causas de la pérdida de tropas}

\section{III.1. Deserción}

El problema más recurrente eran las deserciones. Un $67,7 \%$ de las pérdidas del tercio del Consell de 1667-1668 se debió a tal motivo. El virrey Osuna se vio oligado a lanzar un pregón contra la deserción, castigando con cinco años de galeras para los plebeyos y cinco años de destierro para los caballeros catalanes que ayudasen a huir a los soldados, los ocultasen o les dieran trabajo. También se fijaban recompensas de hasta cincuenta libras para quienes atrapasen y entregasen desertores o informaran sobre quiénes les habían ayudado ${ }^{46}$.

Del tercio de socorro para Girona del Consell, en tres meses de campaña, tuvo 46 deserciones sobre un total de 594 efectivos $-7,74 \%$ de pérdidas por este motivo ${ }^{47}$. El maestre de campo del tercio de Barcelona, J. Grimau, reclamaba al inicio de la campaña mano dura con los desertores, "perque si al principi no sen fa demostració es causa de moltas altras fugas" ${ }^{\prime \prime 8}$.

En 1689, el veedor del tercio del Consell, Onofre Sidós, en su primer viaje al frente para pagar las mesadas, comentó que era necesario dar una recompensa de dos doblas -once libras- a quien atrapase y entregase un desertor al maestre de campo del tercio -por entonces faltaban once hombres. Los conse-

44. ACA, Generalitat, R-123, cartas de ciudades del Principado a los diputats, 12-14-2425-26-IV, catorce cartas del 2 al 28 de mayo y 4-6-17-22-VI-1696. Una de las misivas, de Solsona, le da la razón al virrey Gastañaga en relación a lo mucho pagado otros años como entrada, en su caso hasta 22 libras, de forma que ahora nadie se conformaba con cantidades tan exiguas.

45. ACA, Generalitat, G-119/1, Levas de Cataluña.

46. B(iblioteca) C(ataluña), F(olletos) Bon(soms), Núm. 172.

47. AHMB, Consell, Deliberacions, Vol. 193, 24| de guerra, 9-IX-1684.

48. AHMB, Consell, lletres comunes, Vol. 106, Grimau a los consellers, 3-IV-1684. 
Ilers aceptaron la medida y la sugerencia del propio maestre de campo, don Joaquim Grimau, de buscar en Barcelona algunos desertores, con la intención de dar un escarmiento para evitar más fugas, especialmente a quienes alentaban a otros a huir ${ }^{49}$. Tras los meses más duros de campaña, en septiembre se retornó al problema de la huida de tropas -faltaban veintinueve hombresaprovechando los momentos de respiro. El maestre de campo pedía, de nuevo, mano dura y escarmiento, de lo contrario, "no dupto se desfase en quatro dies tot lo tercio". En realidad, la imagen legada por el Consell en menesteres militares es de una laxitud apabullante, frente a la opinión del maestre de campo Grimau -directamente enfrentado con la realidad- sino dura, sí recta. El Consell llegaba a disculpar a quienes huían y marchaban a Barcelona -donde eran fácilmente localizables- en contraposición a los que se escondían en otras partes de Cataluña. En los días siguientes, fueron atrapados bastantes desertores, sin duda por el interés prestado, pero también por el dinero de la recompensa ${ }^{50}$. No obstante, llegado el momento se sabía ser duro. Por ejemplo, en noviembre de aquel año, se condenó a dos desertores a dos años de prisión con grilletes en una plaza y se rifó entre otros seis una condena a muerte para general escarmiento. La condena se cumplió delante de todo el tercio ${ }^{51}$.

A inicios de 1690, el maestre de campo Grimau insistía al Consell en el sentido de que no pagase a los hombres en la propia Barcelona, por ser este motivo de que muchos escaparan antes de partir al frente. Además, continuaba con su idea de dar un nuevo escarmiento a alguno de los huidos para evitar más fugas ${ }^{52}$.

La situación era tal que en 1693 los consellers daban por bueno que el tercio de socorro de 600 hombres de aquella campaña sólo hubiese tenido 42 desertores -un $7 \%$ del total-, pues era habitual que de los tercios más veteranos desertasen muchos más. Por otro lado, de las levas realizadas aquel mismo año en las veguerías faltaba "la major part de la gent" ${ }^{\prime 3}$. Ante la dificultad para encontrar hombres dispuestos a levarse, especialmente desde 1694, en 1696 y en 1697 se repitieron las órdenes de clemencia a los que regresasen a su tercio, pero tampoco hubo éxito ${ }^{54}$.

En los tercios de la Generalitat hubo problemas y actitudes similares. Normalmente, se enviaba a algún sargento con unos pocos soldados a la caza y captura de desertores del tercio en Barcelona. De hecho, se confeccionaban listas contratando a un escribano en las que incluían todas las señas del huido y

49. AHMB, Consell, Lletres comunes, X-109, O. Sidós al Consell, 9-VI-1689. Idem, Lletres closes, VI-106, consellers a Sidós, 11-VI-1689. AHMB, Lletres comunes, X-109, J. Grimau a consellers, 12-VI-1689.

50. AHMB, Consell, Lletres trameses, VI-107, consellers a Grimau, 12-22-28-IX-1689 y 10-X-1689. Idem, Consell, Lletres comunes, X-109, Grimau a consellers, 12-IX-1689 y 22-IX-1689.

51. AHMB, Consell, Lletres comunes, X-109, J. Montaner a los consellers, 15-XI-1689.

52. AHMB, Consell, Lletres comunes, Vol. 110, Grimau al Consell, 19-1l-1690.

53. AHMB, Consell, Lletres closes, Vol. 109, consellers a su embajador en la Corte, 17-X-1693.

54. AHMB, Consell, Lletres comunes, Vol. 116, maestre de campo al Consell, 9-VIII-1696. 
se enviaban a los diputats locales de la villa o ciudad de la que procedía el ind ividuo para que lo detuviesen si se encontraba allí. Cuando se hacía la leva también se advertía contra el delito de deserción y se informaba de la recompensa, que rápidamente pasó de una libra a cinco y media ${ }^{55}$.

En 1691 hubo bastantes problemas. En abril huyeron siete hombres y tres de ellos se refugiaron en sagrado, en la iglesia de Vidreres, en concreto. El párroco se negaba a entregarlos a menos que se prometiera no castigarlos en acto públ ico. La Generalitat prometió al reverendo Domer que así lo haría ${ }^{56}$. En agosto de aquel año un sargento fue retirado de su compañía y hubo quejas de que algunos ayudantes maltrataban la tropa. Los diputats pidieron al maestre de campo Grimau que vigilase, sobre todo, en "consideració que no es rahó que essent tots naturals ajan de experimentar nostres soldats rigors y maltractament ${ }^{\prime \prime 57}$.

Los diputats estaban convencidos que si su tercio se dividía para enviar hombres de guarnición a alguna plaza, como pretendía hacer el virrey Medina Sidonia en 1691, se fomentaban las deserciones. La vigilancia se imponía. Y por ello, en 1692, se decidió nombrar dos nuevos sargentos para el tercio. Con todo, se supo que algunos desertores del tercio de la Generalitat, a quienes se les había borrado su plaza, es decir, que habían sido oficialmente expulsados, habían aparecido en el tercio del Consell. Dichas situaciones debían terminar ${ }^{58}$. Por ello, en 1692, J. Boneu y E. Bellet, maestre de campo y sargento mayor, respectivamente, del tercio, tenían órdenes estrictas de disciplinar a su gente, evitando en lo posible la concesión de licencias. En octubre se hizo una revista en el Hospital de la Santa Creu de Barcelona enviando al tercio todos los hospitalizados con falsas dolencias. Finalmente, se optó por dejar un oficial en Barcelona encargado de atrapar los desertores que llegasen a la Ciudad Condal y llevarlos de nuevo donde estuviese el tercio. El alférez Picasso fue el elegido, aunque sería un nombramiento erróneo. Ya en 1691 había tenido este oficial algún enfrentamiento con sus superiores y en noviembre de 1692, cuando conducía un contingente de desertores, desertó él, a su vez, siendo atrapado pocos días más tarde. La última medida de aquel año fue expulsar todos los inútiles para el servicio del tercio, promoviendo los buenos soldados que hubiese ${ }^{59}$.

En 1693 la parte negativa fue la recluta de algunos indeseables que desertaron inmediatamente después de cobrar la paga de enganche, asesinando en su huida al batlle de Sant Salvador de Breda. Ante tal situación, el maestre de campo Boneu advirtió a las veguerías que hacían reclutas para impedir el enganche de aquellos desertores en otras compañías para obtener el dinero. $A$

55. ACA, Generalitat, G-121/7, libro de cuentas del tercio, 1689-1692.

56. ACA, Generalitat, Lletres trameses, Vol. 885, diputats al reverendo Domer, 5-IV-1691.

57. ACA, Generalitat, Lletres trameses, Vol. 886, diputats a Grimau, 25-VIII-1691.

58. ACA, Generalitat, Lletres trameses, Vol. 886, diputats al virrey, 18-IX-1691. Ibidem, Vol. 887, diputats al maestre de campo, J. Boneu, 9-VIII-1692.

59. ACA, Generalitat, Lletres trameses, Vol. 886, diputats al Maestre de Campo Boneu, 10-V-1692. Ibidem, Vol. 887, diputats al Maestre de Campo Boneu, 14-17-X y 28-XI-1692. 
pesar de estas experiencias, cuando algún tiempo más tarde se atraparon algunos desertores, los diputats pidieron al maestre de campo que, si bien los hab ría de castigar, lo hiciese "evitant efusió de sanch y mutilació de membres que de eixa manera consentim en que Vostra Merced los mortifique y castigue" ${ }^{\prime 60}$.

Estas permanentes muestras de benignidad pudieron afectar a la disciplina, pero los diputats parece que lo preferían a tener problemas a la hora de reclutar tropas. En cualquier caso, en mayo de 1694 tuvieron que escribir al ayudante del pagador de su tercio para que les aclarase cuántos hombres había realmente en campaña y dónde se encontraban los que faltasen ${ }^{61}$. A partir de 1695 el tema de la disciplina se complicó puesto que algunas compañías levadas por las veguerías de Cataluña pasaron a formar parte del tercio de la Generalitat. Dichas compañías se quejaban de estar muy mal asistidas económicamente, de modo que las huidas estaban a la orden del día ${ }^{62}$. A pesar de que se pagaban dos doblas -diez libras y media- a quien entregase a un desertor y se prometía no castigar al desertor que se presentase voluntariamente antes de quince días, tales medidas tuvieron escaso resultado. El maestre de campo, Marimon, terminó por recomendar, como estaba haciendo el pagador de la compañía de Manresa, que no se diese la cuota de enganche a los levados en Barcelona, porque de ese modo sólo se enrolaban los desertores de otros tercios y los inútiles para elservicio que sólo aspiraban al dinero, sino entregarla en campaña, cuando se hiciese una muestra general del tercio ${ }^{63}$.

\section{III.2. Enfermedad y muerte}

Junto a las deserciones, el principal factor de reducción del número de tropas fueron las bajas por enfermedad, con una incidencia mucho menor de la muerte.

Por otro lado, eran muchos los que iban a la guerra sin tener condiciones para la misma. Poseemos información de 146 casos de soldados considerados inútiles para el servicio en los tercios del Consell entre 1689 y $1697^{64}$. De dicha cifra, $32(21,9 \%)$ fueron declarados inútiles; sin especificar causa había 20 casos, seis eran mancos y otros seis deficientes mentales ${ }^{65}$. Todos fueron descu-

60. ACA, Generalitat, Lletres trameses, Vol. 887, diputats a don Esteve Bellet, 27-Vl-1693. Ibidem, Vol. 887, diputats a don J. Boneu, 3-VII-1693. Ibidem, Vol. 888, diputats a don J. Boneu, 27-VIII-1693.

61. ACA, Generalitat, Lletres trameses, Vol. 888, diputats a J. Fontanills, 15-V-1694.

62. ACA, Generalitat, R-122, jurats de Reus a la Generalitat, 7-VIII-1695 y ACA, Generalitat, R-122, Maestre de campo a los diputats, 9-VIII-1695. El maestre de campo, Marimon, reclamaba que ya era hora de dar un escarmiento a algunos desertores. La Generalitat se limitó a comunicar a las veguerías que promulgasen bandos contra la deserción.

63. ACA, Generalitat, Lletres trameses, Vol. 889, diputats a Marimon, 20-VIII-1695. Ibidem, Marimon a diputats, 23-VIII-1695.

64. AHMB, Consell, Deliberacions, Vols. 198 a 206, 1689-1697.

65. Las fórmulas empleadas en la documentación de la época son "ser simple" o "ser tocat del enteniment". Un caso especial fue el del soldado J. Font que queda "simple" tras ser golpeado en la cabeza por un oficial. 
biertos en plena campaña, lo que indica la falta de seriedad a la hora de hacer la recluta, importando únicamente llenar los cupos asignados. A causa de alguna enfermedad hubo 97 soldados dados de baja $(66,4 \%)$ : en 51 casos lo fueron por diversos padecimientos, pero en once fue por una hernia y en 18 por enfermedades crónicas de las piernas - producto del esfuerzo de la campaña y las la rgas marchas-, hubo cinco casos de epilepsia, cinco de tisis, otros cinco de asma, de fiebres -paludismo- cuatro, otros cuatro de lepra y sólo tres de enfermedades venéreas ${ }^{66}$. Sobresale un caso de neurosis de guerra, el de F. Gasapera que padecía "intervalos de entendimiento y dolor de corazón". En cualquier caso, había un porcentaje importante de personas manifiestamente incapaces para el servicio que eran reclutadas. Los casos más escandalosos son, posiblemente, los de personas de edad avanzada y con problemas en la vista, como ocurrió con el soldado F. Batet que, según un informe, estaba ciego desde hacía varios años. El motivo de estas reclutas era, además del ya mencionado, muy posiblemente Ia necesidad de lograr unos ingresos por parte de gentes que, por sus propias condiciones físicas, quizás los obtendrían con dificultad en el mercado de trabajo.

Revisando casos particulares, los resultados son sorprendentes: M. Muñoz fue retirado "por ser simple y no poder-li encomanar un puesto"; P. Ribes y P. Coll se habían enrolado con sesenta y setenta años, respectivamente, no pudiendo seguir la marcha del tercio. J. Berfull fue rechazado por "no tenir forsas ni esperit per ser soldat"; J. Estevanell "per estar cansats de ensenyar-li lo que convé al servey del Rey y no és estat possible el poder-li enssenyar". M. Carol, por ejemplo, "és de ningún servey per estar continuament borratxo y no se li pot fiar cosa si no lo durmir"67.

En julio de 1693 ocurrió algún percance serio en el seno del tercio "viejo" de la ciudad, es decir, el tercio original concedido como servicio en 1689. El capitán Mujal habló de "desorden", de forma tan alarmante que el Consell envió a don Francisco Vila para inspeccionarlo. Explicaba éste que intentó apaciguar los ánimos, requisando a todos los hombres los cuchillos y las pistolas. El tercio se hallaba en Girona y es muy posible que el mencionado altercado estuviese relacionado con cierta tirantez entre la población civil y los soldados. En cualquier caso, Vila impuso que todos los hombres durmiesen en el cuartel de Girona y no en casas particulares, intentando la acogida de los enfermos en el hospital de la Ciudad. "Del Vicario General del Exército he sacado permiso

66. En estos tercios, el principal vicio parece ser el juego. Muchos soldados se gastaban las pagas en el juego y luego no tenían medios para comprar comida por lo que, a la larga, enfermaban. Cuando, en 1694, se buscaban sustitutos para ayudante de tercio, los diputats le pedían al maestre de campo de su tercio, J. Boneu, que "sian personas que no sian jugadors y que sien exemps dels altres vicis..." . ACA, Generalitat, Lletres trameses, Vol. 888, diputats a Boneu, $10-\mathrm{XI}-1694$.

67. AHMB, Consell, Deliberacions, Vols. 198 a 206, 1689-1697. Véase nuestro trabajo: "Enfermedad y muerte en el ejército de Cataluña durante la Guerra de los Nueve Años, 16891697", en Dynamis, Núm. 16, Granada, 1996, ps. 427-444. 
para que los viernes y sábados puedan comer carne los soldados. Del cuartel he mandado sacar todo lo que era de perjuicio a la salud de los soldados. Se dice el rosario todos los días. Yo vivo y duermo entre ellos para asigurar la quietud y la puntualidad en todo...". Para dar ejemplo condenó a un desertor a ser arcabuceado, conmutándole la pena, a instancias del obispo de Girona, sólo tres horas antes de cumplirse la sentencia. F. Vila expuso, además, que debían eliminarse los permisos por enfermedad, pues la mayoría alegaba cualquier cosa para irse a curar a Barcelona. Si había enfermos leves se restablecerían en el frente o en la guarnición; si la enfermedad era grave, el soldado podría morir por el camino y por ello instó a la permanencia en el acuartelamiento donde se encuentre ${ }^{68}$.

En otro interesante informe, F. Vila explicaba al Consell que, tras pasar una revisión general, el cirujano y él se habían quedado asombrados por el número de hombres enfermos, la mayoría con padecimientos de antes de salir a campaña, quienes "hasta agora no han scido (sic) buenos sino por tomar el socorro y no lo admiro que con el motivo de hacerse tan aprisa la leva del tercio fuese ocasión de lo que sucede haber dado estos hombres las cofradías, pero juzgo redunda en deservicio del rey..." ${ }^{\prime \prime 9}$.

En los tercios de la Generalitat, de 1678 a 1697, hemos encontrado 36 casos de soldados dados por inútiles para el servicio: 17 por alguna enfermedad -entre ellos un cojo descubierto en campaña-, 13 a causa de la necesidad que tenía su familia de su presencia - a menudo padres ancianos que necesitan más a sus hijos que el dinero que éstos pudieran remitirles-, en tres casos se les expulsó por mal comportamiento y en otros tres casos no se especifica el motivo ${ }^{70}$.

Las instituciones catalanas hicieron gala de una cierta liberalidad a la hora de la concesión de licencias para las tropas. Todos los enfermos podían regresar a sus casas a curarse, cobrando allí su soldada. Otra opción era el cobro de parte del salario por los familiares del soldado que lo cuidaban. A menudo, más que a un cierto altruismo, las malas condiciones en los hospitales obligaban a tomar tales medidas. En 1684, por ejemplo, ante las muchas enfermedades propagadas en Girona, hasta 17 hombres del tercio de la Generalitat fueron enviados a casa para curarse ${ }^{71}$. Quienes morían, incluso, no sólo tenían derecho a que se les facilitase el medio de testar antes de morir, sino que además sus albaceas cobraban el dinero que se les adeudara por pagas atrasadas. Además, el pagador del tercio tenía una partida de dinero dispuesta para pagar misas por las almas de los soldados difuntos. Normalmente, los capellanes de los tercios o los religiosos que atendían los hospitales eran elegios como albaceas ${ }^{72}$.

68. AHMB, Consell, Lletres closes, Vol. 113, F. Vila al Consell, 22-VII-1693.

69. AHMB, Consell, Cartes comunes, Vol. 113, don F. Vila al Consell, 9-VIII-1693.

70. En 1684, siete soldados del tercio de la Generalitat alegaron que "tenen obligacions de ajudar a sos pares ab son treball".

71. ACA, Generalitat, Lletres trameses, Vol. 882, diputats al virrey, 21-VIII-1684.

72. ACA, Generalitat, G-121/7, G-121/8, G-121/9, libros de cuentas del tercio, 1689-1697. 
En el siguiente cuadro se pueden apreciar, comparando datos de diferentes años, las principales causas de pérdida de tropas.

\begin{tabular}{lrrrr}
\hline \multicolumn{5}{c}{ Cuadro 4: Pérdida de tropas, 1673-1695. } \\
\hline Tercio/Fecha & Bajas & Deserción & Enfermedad & Muertos \\
Barcelona/1673-4 & 687 & $250(36,3 \%)$ & $327(47,5 \%)$ & $34(04,9 \%)$ \\
Barcelona/1674-5 & 298 & $91(30,5 \%)$ & $169(56,7 \%)$ & $22(07,3 \%)$ \\
Barcelona/1676-7 & 269 & $188(69,8 \%)$ & $62(23,0 \%)$ & $7(02,6 \%)$ \\
Barcelona/1677-8 & 259 & $134(51,7 \%)$ & $90(34,4 \%)$ & $28(10,8 \%)$ \\
Generalitat/1693(a) & 77 & $22(28,5 \%)$ & & $5(06,4 \%)$ \\
Barcelona/1693 & 194 & $42(21,6 \%)$ & $45(23,1 \%)$ & $107(55,1 \%)$ \\
Barcelona/1694-5 & 1.071 & $329(30,7 \%)$ & $303(28,2 \%)$ & $29(02,7 \%)$ \\
$3^{\text {o Copons/1695 }}$ & 331 & $247(74,6 \%)$ & $59(17,8 \%)$ & $18(05,4 \%)$ \\
$3^{\circ}$ Darnius/1695 & 232 & $159(68,5 \%)$ & $54(23,2 \%)$ & $9(03,8 \%)$ \\
\hline
\end{tabular}

Fuente: AHMB, Consellers, Guerra, C-XVI-13, C-XVI-14, C-XVI-17, C-XVI18; ACA, Generalitat, G-119/1 y G-119/2.

(a) Compañía del capitán Viladomar.

Las cifras prueban de forma indiscutible la baja mortalidad causada por la guerra -se puede hablar, incluso, de una mortalidad indirecta superior a la directa, causada por el combate. Por otro lado, las características de la campaña influyen en el resultado de las bajas por enfermedad y por deserción, ello en lo que respecta a los resultados de 1674 a 1678. En 1695, lo sucedido a los tres tercios representados es muy diferente. El tercio de la ciudad de Barcelona, como veterano, tuvo una mayor responsabilidad en campaña, de ahí que presente tantos enfermos como huidos, prácticamente. En cambio, los tercios de nueva formación, como es el caso del del conde Darnius y el de don Joan Copons, apenas si entraron en combate, o estuvieron en puestos menos arriesgados, mientras su disciplina era inferior. Ello explica tanto el alto número de desertores como el bajo porcentaje de enfermos.

\section{III.3. Concesión de licencias}

Aunque no fuese un motivo directo de pérdida de tropas, muy a menudo se concedían licencias por motivos estrictamente personales, de modo que la potencia numérica del tercio disminuía. Además, era bastante corriente conceder el perdón a quienes no regresaban al tercio en el momento de expirar la licencia o se marchaban sin permiso del mismo, transformando esa deserción en una ausencia por licencia que, evidentemente, ni se había demandado ni se había concedido. El abuso fue muy extendido y las soluciones o no se aplicaron o no se quisieron aplicar. El propio virrey Villahermosa, en 1689, criticó la generosidad en las licencias concedidas, cuando él aún no había decretado el 
final de la campaña, justificando la Generalitat lo sucedido escudándose en la falta de experiencia del maestre de campo de su tercio don Joaquim de Marimon $^{73}$. Pero, por ejemplo, se sabía que algunos hombres del tercio del Consell llevaban hasta ocho meses cobrando en la Ciudad como enfermos. Por ello, se pedía que se les licenciase por inútiles para el servicio. Aún peor, algunos soldados con licencia en Barcelona llegaban a cometer robos y otros desórdenes que no se podían permitir ${ }^{74}$.

A pesar de los abusos, algunos ejemplos nos permiten hablar de un trato esquisito para con los soldados que se prolongó a lo largo de los años. El soldado Llorens, en 1691, obtuvo su licencia al estar su madre a punto de mori $y$ deseaba verlo. El soldado Busquets obtuvo la suya para visitar a su mujer que estaba enferma. El soldado Santmartí pidió perdón por su ausencia indebida alegando que se marchó al tener noticias de la posible muerte de su padre. Josep Grau pudo regresar a Barcelona para enterrar a un hijo y casar a una hermana $^{75}$.

73. ACA, Generalitat, Dietari, Vol. 85, Villahermosa a diputats, 28-X-1689. Idem, Lletres trameses, Vol. 884, diputats al virrey, 30-X-1689.

74. AHMB, consellers, Lletres closes, Vol. 107, consellers al maestre de campo, 22-1II-1690. AHMB, Consell, Lletres comunes, Vol. 112, maestre de campo al Consell, 8-X-1692.

75. ACA, Generalitat, Lletres trameses, Vols. 884-886, 1689-1692. 
